
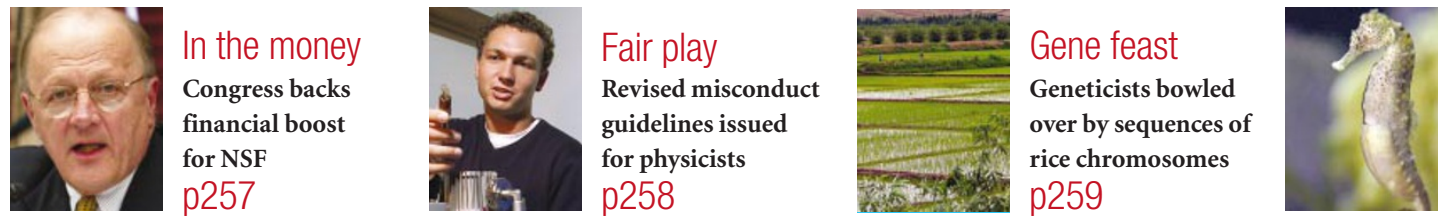

\title{
Biologists divided over proposal to create human-mouse embryos
}

\section{Natalie DeWitt, New York}

Human embryonic stem cells should be injected into mouse embryos to test the cells' likely clinical usefulness, some prominent US developmental biologists say. But the suggestion of creating such mixed-species embryos is likely to provoke public disquiet, and could galvanize political opposition to all research involving human embryos.

The idea was put forward on 13 November at a forum in New York, held to discuss standards for research with human embryonic stem cells. Ali Brivanlou, a developmental biologist at Rockefeller University in New York, and other supporters of the suggestion said that the 'chimaeric' embryos are needed to test the pluripotency of existing lines of human embryonic stem cells. Pluripotency — the ability to divide into cells of different functions, such as muscle or brain cells - is an important measure of the likely clinical usefulness of embryonic stem cells, a unique class of cells that can develop in different ways to perform many such functions.

But the forum, which was organized by the New York Academy of Sciences and Rockefeller University and included several US stem-cell researchers, failed to back a discussion document that would have included a call for the chimaeric embryos to be produced.

For years, mouse embryologists have tested pluripotency by injecting cells into a very early stage mouse embryo called a blastocyst, which consists of a hollow ball of cells. If the injected cells integrate into the embryo and contribute to the formation of every tissue, including the germ line which produces sperm and eggs, then they are pluripotent.

Ethical considerations would preclude an experiment that injected human cells into human embryos. But if they are compatible, cells from different mammalian embryos can be combined to form a viable chimaeric embryo. So some researchers are suggesting that the pluripotency of human embryonic stem cells could be tested by injecting them into mouse embryos. These embryos would then be reimplanted into a female mouse and allowed to develop. The tissues would be dissected and examined at various stages of development to see if they contained human cells.

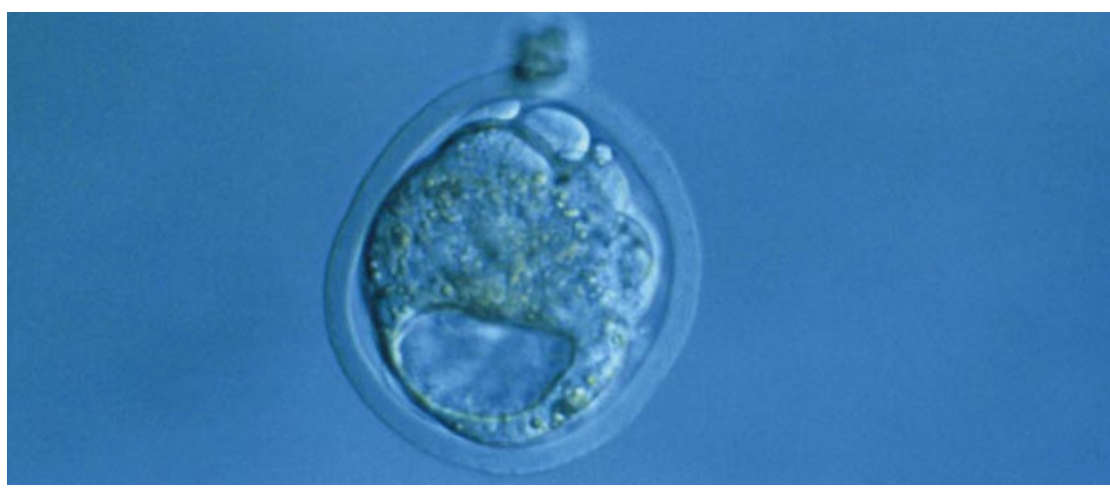

All mixed up: should human embryonic stem cells be fused with mouse blastocysts (pictured)?

But the New York meeting ended without agreement on the issue. Ronald McKay, a leading stem-cell researcher at the National Institute of Neurological Disorders and Stroke (NINDS) in Bethesda, Maryland, said that he flatly opposed a draft document circulated at the meeting that contained the chimaera proposal. "I am completely opposed to putting human embryonic stem cells into any condition that will cause moral affront," he said.

James Battey, a developmental biologist at NINDS and chair of the influential National Institutes of Health (NIH) Stem Cell Task Force, was excluded from a closed session held at the meeting on the discussion paper, and criticized participants for what he regards as excessive secrecy. Battey added that the group, which included prominent researchers such as Fred Gage of the Salk Institute for Biological Studies in La Jolla, California, and Harvard's Douglas Melton, was not fully representative of the field. James Thomson of the University of Wisconsin at Madison, who first isolated human embryonic stem cells, and Austin Smith of the University of Edinburgh, UK, were invited but did not attend, and human embryonic stem-cell experts from Australia and Israel were not invited.

During the open part of the discussion, Janet Rossant of the Mount Sinai Hospital in Toronto questioned whether making interspecies chimaeras was scientifically informative, claiming that in such experiments, "success is meaningful but failure is not". For one thing, she said, the different gestation periods for mice and humans may make it unlikely that the cells will combine in the embryo.

Rossant said there were viable alternatives to making interspecies chimaeras, such as assessing how the embryonic stem cells behave in culture, or testing whether they can engraft and form different tissues after injection into adult mice or mouse fetuses.

None of these tests would present the same ethical problems as producing chimaeras, Battey says. "Generally, the further along in development the fetus is, the less ethically complex these procedures are," he says.

Currently there are no NIH guidelines on any of these types of experiments. But an official at the agency says that they are generally viewed as ethically acceptable if they are done with embryos after the period of gonadal development has passed, so there was no danger, for example, of creating mouse sperm containing human DNA.

Experiments in which the cells of different species are combined in an embryo are likely to become more common as technology advances, researchers say. In September, Nissim Benvenisty of the Hebrew University of Jerusalem reported that he had grafted human embryonic stem cells into 1.5-2-dayold chick embryos (R. S. Goldstein, M. Drukker, B. E. Reubinoff and N. Benvenisty Dev. Dynam. 225, 80-86; 2002). And Huizhen Sheng of Shanghai Second Medical University has transferred the genetic material of human cells into rabbit eggs (see Nature 419,334-336;2002). 